\title{
Association of annexin A5 polymorphisms with obesity
}

\author{
HOSIK SEOK $^{1 *}$, HAE JEONG PARK ${ }^{1 *}$, BYOUNG WOOK LEE $^{2}$, JONG WOO KIM $^{3}$, MIN JUNG $^{4}$, \\ SEO RA LEE ${ }^{4}$, KI HO PARK ${ }^{4}$, YOUNG GUK PARK ${ }^{4}$, HYUNG HWAN BAIK $^{2}$ and JOO-HO CHUNG ${ }^{1}$ \\ Departments of ${ }^{1}$ Pharmacology and Kohwang Medical Research Institute, ${ }^{2}$ Biochemistry and Molecular Biology \\ and ${ }^{3}$ Neuropsychiatry, School of Medicine; ${ }^{4}$ Department of Orthodontics, School of Dentistry, \\ Kyung Hee University, Seoul 130-701, Republic of Korea
}

Received March 21, 2013; Accepted May 10, 2013

DOI: $10.3892 /$ br.2013.118

\begin{abstract}
Annexin A5 (ANXA5), which is known as a protein with anticoagulative function, may play a role in triglyceride biosynthesis. Triglycerides are involved in lipid and energy metabolism, which are important in the elucidation of obesity. To investigate the association between single-nucleotide polymorphisms (SNPs) of ANXA5 and obesity in a Korean population, 372 participants (213 overweight/obese individuals and 159 control subjects) were enrolled from the Kyung Hee University Medical Center and Keimyung University Dongsan Medical Center. The genotypes of five SNPs (rs12510548, rs4240260, rs3756281, rs13136094 and rs6534313) were evaluated in ANXA5 using the multiple logistic regression analysis with the codominant 1 , codominant 2 , dominant, recessive and log-additive models. The genotype and allele frequencies of the five investigated SNPs exhibited significant differences between the control and the overweight/obese groups: rs12510548 $(\mathrm{P}=0.004$ in the codominant 2 model, $\mathrm{P}=0.0019$ in the recessive model, $\mathrm{P}=0.027$ in the log-additive model and $\mathrm{P}=0.026$ in allele frequencies); rs4240260 ( $\mathrm{P}=0.002$ and Fisher's exact $\mathrm{P}=0.0006$ in the codominant 2 model, $\mathrm{P}=0.0007$ and Fisher's exact $\mathrm{P}=0.0007$ in the recessive model, $\mathrm{P}=0.020$ and Fisher's exact $\mathrm{P}=0.0019$ in the log-additive model and $\mathrm{P}=0.020$ in allele frequencies); $r 3756281(\mathrm{P}=0.016$ in the codominant 2 model and $\mathrm{P}=0.0094$ in the recessive model); rs13136094 $(\mathrm{P}=0.0030$ and Fisher's exact $\mathrm{P}=0.0011$ in the codominant 2 model, $\mathrm{P}=0.0012$ and Fisher's exact $\mathrm{P}=0.0013$ in the recessive model, $\mathrm{P}=0.034$ and Fisher's exact $\mathrm{P}=0.0035$ in the log-additive model and $\mathrm{P}=0.024$ in allele frequencies); and rs6534313 $(\mathrm{P}=0.0010$ and Fisher's exact $\mathrm{P}=0.0003$ in the
\end{abstract}

Correspondence to: Dr Joo-Ho Chung, Department of Pharmacology and Kohwang Medical Research Institute, School of Medicine, Kyung Hee University, Hoegi-dong, Dongdaemun-gu, Seoul 130-701, Republic of Korea

E-mail: jhchung@khu.ac.kr

*Contributed equally

Key words: annexin A5, haplotype, obesity, single-nucleotide polymorphism codominant 2 model, $\mathrm{P}=0.0003$ and Fisher's exact $\mathrm{P}=0.0003$ in the recessive model, $\mathrm{P}=0.0075$ and Fisher's exact $\mathrm{P}=0.0010$ in the log-additive model and $\mathrm{P}=0.005$ in allele frequencies). Two haplotypes were weakly associated with obesity (GGATG, $\mathrm{P}=0.037$ and CAGCC, $\mathrm{P}=0.020$ ). Results of the present study suggested that ANXA5 may be associated with the development of obesity in a Korean population.

\section{Introduction}

Obesity has increased epidemically and is currently an important global health problem, since numerous individuals may be classified as overweight or obese (1). Obesity is commonly assessed by calculating the body mass index (BMI) [weight $/\left(\right.$ height) ${ }^{2}$ in $\mathrm{kg} / \mathrm{m}^{2}$ ] (2). According to the World Health Organization guidelines regarding BMI revised for Asian populations, individuals with $\mathrm{BMI} \geq 23 \mathrm{~kg} / \mathrm{m}^{2}$ are classified as overweight, whereas those with $\mathrm{BMI} \geq 25 \mathrm{~kg} / \mathrm{m}^{2}$ are defined as obese (3). Multiple genes, environmental factors and gene-environment interactions play crucial roles in obesity and in the tendency to gain weight. Although the maintenance of body weight is under genetic control, mutations in a single gene rarely result in severe obesity (4). Previous studies reported associations between BMI or obesity and genetic variants, suggesting that polymorphisms in the genes linked to various pathways may contribute to the development of obesity (5-7).

The annexin A5 gene (ANXA5), mapped to the chromosome $4 \mathrm{q} 28-\mathrm{q} 32$, is $1.6-\mathrm{kb}$ long and contains 13 exons that code for a polypeptide chain of 320 amino acids $(8,9)$. ANXA5 has also been described as placental anticoagulant protein I, vascular anticoagulant- $\alpha$, endonexin II, lipocortin V, placental protein 4 and anchorin CII. ANXA5 is a member of the annexin family of calcium-dependent phospholipid-binding proteins (10). In addition, a previous study by Dennis et al (11) reported that ANXA5 may affect triglyceride metabolism. These results suggested that an association between ANXA5 and lipid metabolism may be an important aspect of obesity. However, the genetic role of ANXA5 in obesity has not been fully elucidated. To the best of our knowledge, there is only one available association study on ANXA5 single-nucleotide polymorphism (SNP), which reported that the intronic SNPs (iSNPs) rs4833229 and rs6830321 were associated with 
Table I. Demographic and clinical characteristics of study subjects.

\begin{tabular}{lccr}
\hline Variables & Control $(\mathrm{n}=159)$ & Overweight/obese $(\mathrm{n}=213)$ & P-value \\
\hline Age $($ years $)$ & $43.43 \pm 6.08$ & $44.79 \pm 6.40$ & 0.042 \\
BMI $\left(\mathrm{kg} / \mathrm{m}^{2}\right)$ & $21.15 \pm 1.21$ & $25.59 \pm 2.03$ & $<0.001$ \\
SBP $(\mathrm{mmHg})$ & $115.53 \pm 16.17$ & $123.89 \pm 17.57$ & $<0.001$ \\
DBP $(\mathrm{mmHg})$ & $71.88 \pm 10.37$ & $77.66 \pm 11.19$ & $<0.001$ \\
Fasting plasma glucose $(\mathrm{mg} / \mathrm{dl})$ & $90.10 \pm 11.62$ & $93.81 \pm 14.86$ & $<0.001$ \\
HbA 1 (\%) & $5.34 \pm 0.41$ & $5.47 \pm 0.66$ & 0.037 \\
TG $(\mathrm{mg} / \mathrm{dl})$ & $97.79 \pm 56.88$ & $140.39 \pm 118.28$ & $<0.001$ \\
TC $(70 \mathrm{mg} / \mathrm{dl})$ & $186.10 \pm 29.92$ & $196.24 \pm 33.66$ & 0.003 \\
LDL-C (mg/dl) & $109.08 \pm 28.92$ & $118.31 \pm 31.43$ & 0.004 \\
HDL-C $(\mathrm{mg} / \mathrm{dl})$ & $56.83 \pm 13.25$ & $49.85 \pm 11.37$ & $<0.001$
\end{tabular}

Data are presented as mean \pm standard deviation. BMI, body mass index; SBP, systolic blood pressure; DBP, diastolic blood pressure; HbA ${ }_{1 \mathrm{C}}$, glycosylated hemoglobin; TG, triglyceride; TC, total cholesterol; LDL-C, low-density lipoprotein cholesterol; HDL-C, high-density lipoprotein cholesterol.

restenosis in patients who had undergone percutaneous coronary intervention (PCI) (12). Taking into consideration that the role of ANXA5 in coagulation is linked to triglyceride biosynthesis (11), we hypothesized that $A N X A 5$ SNPs may affect the development of obesity.

To the best of our knowledge, the association between ANXA5 polymorphisms and obesity has not been previously investigated. The aim of this study was to investigate whether ANXA5 SNPs were associated with obesity in a Korean population.

\section{Subjects and methods}

Subjects. A total of 213 overweight/obese (BMI $\left.\geq 23 \mathrm{~kg} / \mathrm{m}^{2}\right)$ and 159 control $\left(18.0<\mathrm{BMI}<23 \mathrm{~kg} / \mathrm{m}^{2}\right)$ subjects were recruited from Kyung Hee University Medical Center and Keimyung University Dongsan Medical Center. All the subjects were ethnic Korean. Their demographic and biochemical characteristics are shown in Table I. DNA was isolated from peripheral blood using the G-DEX ${ }^{\mathrm{TM}}$ IIb Genomic DNA Extraction kit (iNtRON Biotechnology, Seongnam, Korea). Collection of the subjects was performed according to the Declaration of Helsinki guidelines. All the subjects provided written informed consent prior to enrollment, and informed consent was obtained by legal guardians of the patients if they were of minor age. This study was approved by the the ethics review committee of the Medical Research Institute, School of Medicine, Kyung Hee University and the Institutional Review Board of Kyung Hee University Medical Center, Seoul, Korea.

SNP selection and genotyping. Five iSNPs within the ANXA5 gene were selected as follows: SNP tagging was performed using the tagging option of the Tagger program (http://www. broad.mit.edu/mpg/tagger/) with known heterozygosity and minor allele frequency >0.05 (http://www.hapmap.org) Genotyping was performed with the Affymetrix Targeted Genotyping Chip array (Affymetrix, Santa Clara, CA, USA) according to the manufacturer's instructions. Each genotyping was analyzed using GCOS software (Affymetrix).

Statistical analysis. The Hardy-Weinberg equilibrium (HWE) was assessed for each of the five selected SNPs using the SNPStats software (13). The linkage disequilibrium (LD) block of the five selected SNPs was assessed using Haploview software version 4.1 (14). Multiple logistic regression models were performed for the odds ratios (ORs), $95 \%$ confidence intervals (CIs) and corresponding P-values, controlling for age and gender as covariables (15). The Student's unpaired t-test was used for assessing statistical differences in age, BMI, systolic blood pressure (SBP), diastolic blood pressure (DBP), fasting plasma glucose, glycosylated hemoglobin $\left(\mathrm{HbA}_{1 \mathrm{c}}\right)$, triglycerides (TG), total cholesterol (TC), low-density lipoprotein cholesterol (LDL-C) and high-density lipoprotein cholesterol (HDL-C) between the control and the overweight/obese groups. SPSS software version 18.0 (SPSS, Inc., Chicago, IL, USA) was used to analyze statistical significance.

\section{Results}

Demographic and clinical characteristics of the study subjects. The demographic and clinical characteristics, i.e., age, BMI, SBP, DBP, fasting plasma glucose, $\mathrm{HbA}_{1 \mathrm{c}}$, TG, TC, LDL-C and HDL-C, were significantly different between the control and overweight/obese subjects $(\mathrm{P}<0.05$, Table I), with some of the clinical characteristics, including BMI, SBP, DBP, fasting plasma glucose, TG and HDL-C, exhibiting more statistically significant differences $(\mathrm{P}<0.001)$ (Table I). The genotype distributions of the five selected SNPs were in HWE ( $\mathrm{P}>0.05$, data not shown).

Genotype and allele frequencies of ANXA5 SNPS. The genotype and allele frequencies of the investigated SNPs (rs12510548, rs4240260, rs3756281, rs13136094 and rs6534313) are provided in Table II. The genotype frequencies of the five selected SNPs exhibited protective effects on 
Table II. Genotype and allele frequencies of ANXA5 SNPs in the control and overweight/obese groups.

\begin{tabular}{|c|c|c|c|c|c|c|c|}
\hline SNP & Type & $\begin{array}{l}\text { Control } \\
{[\mathrm{n}(\%)]}\end{array}$ & $\begin{array}{l}\text { Overweight/ } \\
\text { obese [n (\%)] }\end{array}$ & Model & OR $(95 \% \mathrm{CI})$ & P-value & Fisher's exact $\mathrm{P}$ \\
\hline \multirow{7}{*}{$\begin{array}{l}\text { rs12510548 } \\
\text { intron }\end{array}$} & $\mathrm{G} / \mathrm{G}$ & $71(44.9)$ & $107(51.4)$ & Codominant 1 & $0.93(0.60-1.44)$ & 0.74 & \\
\hline & $\mathrm{C} / \mathrm{G}$ & $68(43.0)$ & $94(45.2)$ & Codominant 2 & $0.25(0.10-0.64)$ & 0.004 & \\
\hline & $\mathrm{C} / \mathrm{C}$ & $19(12.0)$ & $7(3.4)$ & Dominant & $0.78(0.51-1.19)$ & 0.25 & \\
\hline & & & & Recessive & $0.26(0.11-0.64)$ & 0.0019 & \\
\hline & & & & Log-additive & $0.68(0.48-0.96)$ & 0.027 & \\
\hline & G & $210(66.5)$ & $308(74.0)$ & & & & \\
\hline & $\mathrm{C}$ & $106(33.5)$ & $108(26.0)$ & Allele & $0.69(0.50-0.96)$ & 0.026 & \\
\hline \multirow{7}{*}{$\begin{array}{l}\text { rs } 4240260 \\
\text { intron }\end{array}$} & $\mathrm{G} / \mathrm{G}$ & $71(44.9)$ & $108(51.7)$ & Codominant 1 & $0.92(0.59-1.43)$ & 0.71 & \\
\hline & $\mathrm{A} / \mathrm{G}$ & 69 (43.7) & $96(45.9)$ & Codominant 2 & $0.19(0.07-0.55)$ & 0.002 & 0.0006 \\
\hline & $\mathrm{A} / \mathrm{A}$ & $18(11.4)$ & $5(2.4)$ & Dominant & $0.77(0.51-1.18)$ & 0.23 & \\
\hline & & & & Recessive & $0.20(0.07-0.56)$ & 0.0007 & 0.0007 \\
\hline & & & & Log-additive & $0.66(0.47-0.94)$ & 0.020 & 0.0019 \\
\hline & $\mathrm{G}$ & $211(66.8)$ & $312(74.6)$ & & & & \\
\hline & A & $105(33.2)$ & $106(25.4)$ & Allele & $0.68(0.50-0.94)$ & 0.020 & \\
\hline \multirow{7}{*}{$\begin{array}{l}\text { rs3756281 } \\
\text { intron }\end{array}$} & $\mathrm{A} / \mathrm{A}$ & $67(43.2)$ & $90(46.4)$ & Codominant 1 & $1.01(0.64-1.58)$ & 0.98 & \\
\hline & $\mathrm{A} / \mathrm{G}$ & $69(44.5)$ & $95(49.0)$ & Codominant 2 & $0.35(0.15-0.82)$ & 0.016 & \\
\hline & $\mathrm{G} / \mathrm{G}$ & $19(12.3)$ & $9(4.6)$ & Dominant & $0.86(0.56-1.33)$ & 0.51 & \\
\hline & & & & Recessive & $0.35(0.15-0.79)$ & 0.0094 & \\
\hline & & & & Log-additive & $0.75(0.53-1.06)$ & 0.098 & \\
\hline & A & $203(65.5)$ & 275 (70.9) & & & & \\
\hline & G & $107(34.5)$ & $113(29.1)$ & Allele & $0.78(0.57-1.07)$ & 0.13 & \\
\hline \multirow{7}{*}{$\begin{array}{l}\text { rs13136094 } \\
\text { intron }\end{array}$} & $\mathrm{T} / \mathrm{T}$ & $79(50.0)$ & $119(56.4)$ & Codominant 1 & $0.96(0.61-1.48)$ & 0.84 & \\
\hline & $\mathrm{C} / \mathrm{T}$ & $62(39.2)$ & 87 (41.2) & Codominant 2 & $0.21(0.07-0.59)$ & 0.0030 & 0.0011 \\
\hline & $\mathrm{C} / \mathrm{C}$ & $17(10.8)$ & $5(2.4)$ & Dominant & $0.80(0.52-1.21)$ & 0.29 & \\
\hline & & & & Recessive & $0.21(0.08-0.59)$ & 0.0012 & 0.0013 \\
\hline & & & & Log-additive & $0.69(0.49-0.97)$ & 0.034 & 0.0035 \\
\hline & $\mathrm{T}$ & $220(69.6)$ & $325(77.0)$ & & & & \\
\hline & $\mathrm{C}$ & $96(30.4)$ & $97(23.0)$ & Allele & $0.68(0.49-0.95)$ & 0.024 & \\
\hline rs6534313 & $\mathrm{G} / \mathrm{G}$ & $74(49.0)$ & $121(58.2)$ & Codominant 1 & $0.88(0.56-1.37)$ & 0.57 & \\
\hline \multirow[t]{6}{*}{ intron } & $\mathrm{C} / \mathrm{G}$ & $59(39.1)$ & $82(39.4)$ & Codominant 2 & $0.17(0.06-0.50)$ & 0.0010 & 0.0003 \\
\hline & $\mathrm{C} / \mathrm{C}$ & $18(11.9)$ & $5(2.4)$ & Dominant & $0.71(0.46-1.09)$ & 0.12 & \\
\hline & & & & Recessive & $0.18(0.07-0.51)$ & 0.0003 & 0.0003 \\
\hline & & & & Log-additive & $0.62(0.44-0.88)$ & 0.0075 & 0.0010 \\
\hline & $\mathrm{G}$ & $207(68.5)$ & $324(77.9)$ & & & & \\
\hline & $\mathrm{C}$ & $95(31.5)$ & $92(22.1)$ & Allele & $0.62(0.44-0.87)$ & 0.005 & \\
\hline
\end{tabular}

ORs, 95\% CIs, and P-values were from multiple logistic regression analyses with the codominant 1, codominant 2, dominant and recessive models controlling age and gender as covariates. ANXA5, annexin 5; SNP, single-nucleotide polymorphism; OR, odds ratio; CI, confidence interval.

the development of overweight/obesity in the codominant 2 model (rs12510548; OR=0.25, 95\% CI: 0.10-0.64; $\mathrm{P}=0.004)$ (rs4240260; OR=0.19, 95\% CI: 0.07-0.55; P=0.002; Fisher's exact $\mathrm{P}=0.0006)(\mathrm{rs} 3756281 ; \mathrm{OR}=0.35,95 \% \mathrm{CI}: 0.15-0.82$; $\mathrm{P}=0.016) \quad(\mathrm{rs} 13136094 ; \mathrm{OR}=0.21,95 \% \mathrm{CI}: 0.07-0.59$; $\mathrm{P}=0.0030$; Fisher's exact $\mathrm{P}=0.0011)(\mathrm{rs} 6534313 ; \mathrm{OR}=0.17$, 95\% CI: 0.06-0.50; $\mathrm{P}=0.0010$; Fisher's exact $\mathrm{P}=0.0003)$ and recessive model (rs12510548; $\mathrm{OR}=0.26,95 \% \mathrm{CI}$ : 0.11-0.64; $\mathrm{P}=0.0019) \quad(\mathrm{rs} 4240260 ; \mathrm{OR}=0.20,95 \% \mathrm{CI}: 0.07-0.56$;
$\mathrm{P}=0.0007$; Fisher's exact $\mathrm{P}=0.0007)$ (rs3756281; $\mathrm{OR}=0.35$, 95\% CI: 0.15-0.79; $\mathrm{P}=0.0094)(\mathrm{rs} 13136094 ; \mathrm{OR}=0.21$, 95\% CI: 0.08-0.59; $\mathrm{P}=0.0012$; Fisher's exact $\mathrm{P}=0.0013$ ) (rs6534313; OR=0.18, 95\% CI: 0.07-0.51; P=0.0003; Fisher's exact $\mathrm{P}=0.0003$ ). Four out of the five investigated SNPs (rs12510548, rs4240260, rs13136094 and rs6534313) exhibited protective effects in the log-additive model (rs12510548; $\mathrm{OR}=0.68,95 \% \mathrm{CI}: 0.48-0.96 ; \mathrm{P}=0.027)(\mathrm{rs} 4240260 ; \mathrm{OR}=0.66$, 95\% CI: 0.47-0.94; $\mathrm{P}=0.020$; Fisher's exact $\mathrm{P}=0.0019$ ) 
Table III. Haplotypes of the ANXA5 SNPs in the control and overweight/obese groups.

\begin{tabular}{|c|c|c|c|c|c|c|c|}
\hline \multirow[b]{2}{*}{ Haplotype } & \multirow[b]{2}{*}{ Frequency $(\%)$} & \multicolumn{2}{|c|}{ Control } & \multicolumn{2}{|c|}{ Overweight/obese } & \multirow[b]{2}{*}{$\chi^{2}$} & \multirow[b]{2}{*}{ P-value } \\
\hline & & - & + & - & + & & \\
\hline GGATG & 70.2 & 107 & 209 & 114 & 312 & 4.36 & 0.037 \\
\hline CAGCC & 25.7 & 221 & 95 & 330 & 96 & 5.38 & 0.020 \\
\hline CAGTG & 3.6 & 306 & 10 & 409 & 17 & 0.35 & 0.55 \\
\hline
\end{tabular}

Bold numbers indicate statistical significance. ANXA5, annexin 5; SNP, single-nucleotide polymorphism.

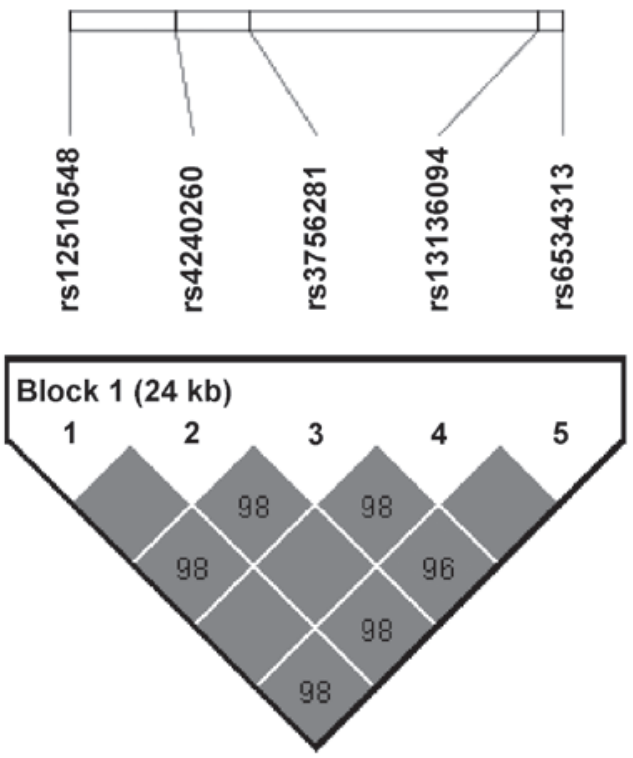

Figure 1. The linkage disequilibrium block consisted of the 5 annexin A5 single-nucleotide polymorphisms (rs12510548, rs4240260, rs3756182, rs13136094 and rs6534313).

(rs13136094; OR=0.69, 95\% CI: 0.49-0.97; P=0.034; Fisher's exact $\mathrm{P}=0.0035$ ) (rs6534313; $\mathrm{OR}=0.62,95 \% \mathrm{CI}$ : 0.44-0.88; $\mathrm{P}=0.0075$; Fisher's exact $\mathrm{P}=0.0010$ ) (Table II).

The allele frequencies of four SNPs (rs12510548, rs4240260, rs13136094 and rs6534313) were significantly different between the control and overweight/obese subjects (rs12510548; OR=0.69; 95\% CI: 0.50-0.96) (rs4240260; $\mathrm{OR}=0.68,95 \% \mathrm{CI}: 0.50-0.94)(\mathrm{rs} 13136094 ; \mathrm{OR}=0.68$, 95\% CI: 0.49-0.95) (rs6534313; OR=0.62, 95\% CI: 0.44-0.87) (Table II). Their minor allele frequencies were $\sim 1.3-1.4$-fold lower in the overweight/obese group compared to the control group and they exerted protective effects on the development of overweight/obesity.

Linkage disequilibrium and haplotypes. Fig. 1 shows an LD block consisting of the five consecutive SNPs (rs12510548, rs4240260, rs3756281, rs13136094 and rs6534313). In the LD block, three haplotypes were formed (GGATG, CAGCC and CAGTG). The frequencies of the GGATG, CAGCC and CAGTG haplotypes were 70.2, 25.7 and $3.6 \%$, respectively, and the results indicated that the GGATG $(\mathrm{P}=0.037)$ and CAGCC $(\mathrm{P}=0.020)$ haplotypes were weakly associated with the development of obesity (Table III).

\section{Discussion}

ANXA5 is an intracellular protein that is abundantly present in endothelial cells and platelets and exhibits high affinity for anionic phospholipids in lipid membranes (16). Based on its affinity, fluorescently-labeled ANXA5 is often used in flow cytometric assays to detect cells undergoing apoptosis, during which the lipid consistency of cell membranes rapidly changes (17). ANXA5 is a potent anticoagulant that regulates exocytosis and syncytiotrophoblast membrane fusion (17) and expression of ANXA5 in cancer tissues is an important factor in tumor infiltration, which is associated with cellular energy metabolism and membrane regulating function (18). ANXA5 protects the lipid membrane barrier against damage due to inflammatory mediators (19) and there is an association between inflammatory molecule levels and visceral obesity (20). These results suggested that ANXA5 may play a role in lipid metabolism.

As regards $A N X A 5$ polymorphisms, there has been only one study on the association of ANXA5 iSNPs (rs4833229 and rs6830321) and the restenosis rate of PCI (12). It may be considered that the role of ANAX5 in coagulation pathways affected the therapeutic consequences of atherosclerotic disease (12). However, that study demonstrated a significant effect exerted by polymorphisms in the intron region of $A N X A 5$, although the two SNPs involved (rs4833229 and rs6830321) were not included in our study.

Our results demonstrated that the five SNPs of ANXA5 included in this study (rs12510548, rs4240260, rs3756182, rs13136094 and rs6534313) were associated with the risk of obesity. In our haplotype analysis results, GGATG and CAGCC were significantly associated with the risk of overweight/obesity, suggesting that ANXA5 may be involved in the development of obesity (21). All the significant SNPs were intronic and unlikely to be directly protein-modifying polymorphisms. However, iSNPs may interfere with the mRNA splicing process and gene expression levels (22). The minor allele frequencies of rs12510548, rs4240260, rs3756281, rs13136094 and rs6534313 in our study population were similar to those in Japanese subjects ( 0.29 vs. $0.21,0.29$ vs. $0.23,0.32$ vs. $0.23,0.26$ vs. 0.22 and 0.26 vs. 0.22 , respectively) in the dbSNP Build 137 of the NCBI database (http://www.ncbi.nlm.nih.gov/SNP/).

In summary, our results suggest that there is an association between the five iSNPs (rs12510548, rs4240260, rs3756182, rs13136094 and rs6534313) of ANXA5 and the development of obesity in a Korean population. To the best of our knowledge, 
this is the first study demonstrating the association of ANXA5 SNPs with the susceptibility to overweight and obesity. Further studies are required to elucidate whether additional ANXA5 SNPs are associated with obesity and determine the precise role of ANXA5 in obesity in different populations.

\section{Acknowledgements}

This study was supported by a grant from the Kyung Hee University (KHU-20090641).

\section{References}

1. Haslam DW and James WP: Obesity. Lancet 366: 1197-1209, 2005.

2. Sachdev HS, Fall CH, Osmond C, et al: Anthropometric indicators of body composition in young adults: relation to size at birth and serial measurements of body mass index in childhood in the New Delhi birth cohort. Am J Clin Nutr 82: 456-466, 2005

3. WHO Expert Consultation: Appropriate body-mass index for Asian populations and its implications for policy and intervention strategies. Lancet 363: 157-163, 2004.

4. Gazzerro P, Caruso MG, Notarnicola M, et al: Association between cannabinoid type-1 receptor polymorphism and body mass index in a southern Italian population. Int J Obes (Lond) 31: 908-912, 2007.

5. Dahlman I and Arner P: Obesity and polymorphisms in genes regulating human adipose tissue. Int J Obes (Lond) 31: 1629-1641, 2007.

6. Duarte SF, Francischetti EA, Genelhu-Abreu V, et al: p.Q223R leptin receptor polymorphism associated with obesity in Brazilian multiethnic subjects. Am J Hum Biol 18: 448-453, 2006.

7. Rankinen T, Zuberi A, Chagnon YC, et al: The human obesity gene map: the 2005 update. Obesity (Silver Spring) 14: 529-644, 2006.

8. Martin SJ, Finucane DM, Amarante-Mendes GP, O'Brien GA and Green DR: Phosphatidylserine externalization during CD95-induced apoptosis of cells and cytoplasts requires ICE/CED-3 protease activity. J Biol Chem 271: 28753-28756, 1996.

9. Bratton DL, Fadok VA, Richter DA, et al: Appearance of phosphatidylserine on apoptotic cells requires calcium-mediated nonspecific flip-flop and is enhanced by loss of the aminophospholipid translocase. J Biol Chem 272: 26159-26165, 1997.
10. Reutelingsperger CP, Hornstra G and Hemker HC: Isolation and partial purification of a novel anticoagulant from arteries of human umbilical cord. Eur J Biochem 151: 625-629, 1985.

11. Dennis MW, Downey C, Brufatto N, et al: Prothrombinase enhancement through quantitative and qualitative changes affecting very low density lipoprotein in complex with C-reactive protein. Thromb Haemost 91: 522-530, 2004.

12. Ewing MM, Karper JC, Sampietro ML, et al: Annexin A5 prevents post-interventional accelerated atherosclerosis development in a dose-dependent fashion in mice. Atherosclerosis 221: 333-340, 2012.

13. Sole X, Guino E, Valls J, Iniesta R and Moreno V: SNPStats: a web tool for the analysis of association studies. Bioinformatics 22: 1928-1929, 2006.

14. Barrett JC, Fry B, Maller J and Daly MJ: Haploview: analysis and visualization of LD and haplotype maps. Bioinformatics 21: 263-265, 2005.

15. Cho AR, Lee SM, Kang WS, et al: Assessment between dopamine receptor D2 (DRD2) polymorphisms and schizophrenia in Korean population. Clin Psychopharmacol Neurosci 10: 88-93, 2012.

16. Willems GM, Janssen MP, Comfurius P, et al: Competition of annexin $\mathrm{V}$ and anticardiolipin antibodies for binding to phosphatidylserine containing membranes. Biochemistry 39: 1982-1989, 2000.

17. Arai T, Matsubayashi H, Sugi T, et al: Anti-annexin A5 antibodies in reproductive failures in relation to antiphospholipid antibodies and phosphatidylserine. Am J Reprod Immunol 50: 202-208, 2003

18. Deng S, Wang J, Hou L, et al: Annexin A1, A2, A4 and A5 play important roles in breast cancer, pancreatic cancer and laryngeal carcinoma, alone and/or synergistically. Oncol Lett 5: 107-112, 2013.

19. Creutz CE, Hira JK, Gee VE and Eaton JM: Protection of the membrane permeability barrier by annexins. Biochemistry 51 : 9966-9983, 2012.

20. Tchernof A and Despres JP: Pathophysiology of human visceral obesity: an update. Physiol Rev 93: 359-404, 2013.

21. Zhu X, Zhang S, Kan D and Cooper R: Haplotype block definition and its application. Pac Symp Biocomput 152-163, 2004

22. Barrett LW, Fletcher S and Wilton SD: Regulation of eukaryotic gene expression by the untranslated gene regions and other non-coding elements. Cell Mol Life Sci 69: 3613-3634, 2012. 